\title{
Determining the differences in nutrition knowledge, dietary behaviors, physical activity and self-efficacy behaviors based on obesity status among adolescents
}

\author{
Seda Cangöl Sögüt ${ }^{1}$
}

\begin{abstract}
Purpose: This study was conducted to specify the differences in nutrition knowledge, dietary behaviors, physical activity, and self-efficacy behaviors based on obesity status among adolescents.

Methods: In the study, descriptive-correlational design type was used. The sample of the study consisted of 530 adolescents and their parents selected among $5^{\text {th }}$ grade students studying in five secondary schools by using the stratified random sampling method. The study data were collected using the Family Information Questionnaire, the Nutrition Knowledge Scale,the Diet Behavior Scale,the Children's Dietary Self-Efficacy Scale and the Exercise Behavior Scale. Adolescents were assessed according to body mass index percentages in overweight - obese and normal weight groups in two groups. SPSS 22 program was used in the analysis of the data. For the data assessment, descriptive statistical methods (mean, median, number, percentage) were used. Pearson's Chi-Square test was applied for comparison of categorical data. The t-test was performed in between-group comparison of parameters.
\end{abstract}

Results: $50.9 \%$ of the adolescents were male and $30 \%$ of them $n=(159)$ were found to be overweight and obese according to BMI. There was no significant difference between the BMI normal, and overweight/obese adolescents according to gender, age, income status and the mother's educational level ( $\mathrm{p}>0.05)$. The difference between BMI normal and overweight/obese children based on Father's Educational Level, Mother's BMI, and Father's BMI values was significant. As educational level of the father and BMI value of mother and father increased, the rate of overweight-obese adolescents also increased $(\mathrm{p}<0.05)$. It was found that adolescents' mean "physical activity behaviors" was $17.457 \pm 3.732$; "nutrition knowledge mean score" was 11,330 \pm 3,258 ; "dietary self-efficacy" mean score was $5.138 \pm 5.386$; "dietary behavior" mean score was $3.694 \pm 5.324$. The adolescents' physical activity behaviors were high, self-efficacy behaviors were good, and nutrition knowledge levels and dietary behaviors were at moderate level. Nutrition knowledge, dietary behaviors, and dietary self-efficacy of overweight and obese adolescents were found to be high $(p<0.05)$. No significant difference was found among the groups based on physical activity behaviors ( $\mathrm{p}>0.05)$.

Conclusion: All adolescents' nutritional knowledge and nutritional behavior scores were moderate. Nutrition knowledge, nutritional behavior and nutrition self-efficacy scores were high in overweight / obese adolescents. This result may be due to the fact that adolescents and parents in the overweight and obese group are more cautious about nutritional behavior. It can be said that obese adolescents can not turn into information behaviors. Attempts can be made for this. In this regard, larger studies can be suggested.

Keywords: Adolescents; obesity; nutrition; physical activity; self-efficacy.

${ }^{1}$ Assist. Prof., Çanakkale Onsekiz Mart University, Çanakkale Health School, Midwifery Department, sdcngl@hotmail.com Submitted: 2018-02-08 Published: 2018-04-18 
Cangöl Sögüt, S. (2018). Determining the differences in nutrition knowledge, dietary behaviors, physical activity and self-efficacy behaviors based on obesity status among adolescents. Journal of Human Sciences, 15(2), 747-754. doi: $10.14687 /$ ihs.v15i2.5218

\section{Introduction}

Obesity in adolescence period is among major public health issues in $21^{\text {st }}$ century. According to WHO, 340 million adolescents aged between 5-18 years are overweight and obese. The number of obese adolescents is increasing ten times more in recent years in the world. If the current trend continues until 2022, it is thought that there will be higher number of obese adolescents (World Health Organization [WHO], 2016). The prevalence of overweight and obesity in the United States of America affects 17\% and approximately 12.7 million adolescents (Centers for Disease Control and Prevention [CDC], 2016). According to the data of Turkey, $14.2 \%$ of the adolescents are overweight and 8.3\% are obese (COSI-TR, 2013). The possibility of overweight and obese children to have chronic health problems such as diabetes, cardiovascular diseases, ischemic heart disease, and cancer at young ages and obese in adulthood increases (CDC, 2016; Ha et al., 2016; WHO,2016). However, obese individuals may experience social, emotional disorders and low self-esteem. This is because prevention of obesity at an early age is important.

While the efforts to prevent obesity are important in every period of life, this importance is increasing even more in the early adolescence period where growth and development accelerate and learning and comprehension functions become important. In addition, there is a high risk that erroneous eating habits in this period may be reflected to adulthood period (TOÇBİ, 2011).

In studies investigating the effect of nutrition knowledge on health behaviors of children, dietary behavior scores of children with high nutrition knowledge and attitude scores were found to be high (Wagner and Bear, 2009; Forneris et al., 2010).

Participation in physical activities increases the control on the anxiety and depression symptoms and helps to the self-expression, self-confidence and social development of children. Therefore, performing physical activity of minimum 60 minutes between the ages of 5-17 years is recommended for weight management (WHO, 2016).

Self-efficacy demonstrates self-confidence of an individual about behavioral change. Dietary self-efficacy is the efficacy level perceived by the individual as choosing healthier foods and is a factor that must be examined in the planning of nutritional interventions (Di Noia, Schinke, Prochaska, and Contento 2006; Horwath, Nigg, Wong, and Dishman, 2010). In preventing the obesity in adolescents, determination of dietary behaviors and the associated factors at an early period is important since it leads to interventions to be made in order to prevent or control the obesity.

In this study, it was aimed to determine the differences in nutrition knowledge, dietary behaviors, physical activity, and self-efficacy behaviors in terms of obesity status among adolescents.

\section{Method and Material}

\subsection{Design}

Descriptive-correlational design type was used in the study.

\section{2.Participants and Procedure}

The population of the study consisted of $5^{\text {th }}$ grade students $(N=2993)$ studying at secondary schools affiliated with Uşak Provincial Directorate of National Education. The sample of the study was selected from the fifth-grade students $(\mathrm{n}=2993)$, who had no chronic disease and agreed to participate in the study, via the stratified random sampling method. The sample size was calculated by carrying out the power analysis $(\alpha: 0.05,1-\beta=0.80)$. According to the stratum weight, the sample is composed of 380, 115 and 35 students from a public secondary school, a religious secondary school and a private secondary school, respectively. The purpose was to reach a mosaic group for obesity prevention programs covering different family structure- education and culture. A random number table was used to select students from the strata. The study was carried out between January and December 2014. The measurement tools were filled by the students 
Cangöl Sögüt, S. (2018). Determining the differences in nutrition knowledge, dietary behaviors, physical activity and self-efficacy behaviors based on obesity status among adolescents. Journal of Human Sciences, 15(2), 747-754. doi:10.14687/jhs.v15i2.5218

independently and they were allowed to ask questions. Their heights and weights were measured. The adolescents were divided into overweight - obesity and normal weight groups based on their body mass index percentages. A Family Information Questionnaire was sent to the parents in a closed envelope to be filled.

\subsection{Instruments}

\subsubsection{Family Information Questionnaire}

This questionnaire was prepared by the researchers upon the literature review. It included the adolescents' age, gender and BMI values and parents' educational levels, income status, and BMI values. For age and gender, the children were categorized as underweight $(<5$ p.), normal $(5-$ 85 p.), overweight $(85-95$ p.), and obesity or obese (>95 p.) based on BMI (kg/m2) reference values published by Bundak et al., (2006) for Turkish children. Self-reported weight and height values were used to calculate BMI values of the parents. Educational levels of the parents were specified as (1) low ( $\leq 5$ years), (2) moderate (6-11 years), and (3) high ( $\geq 12$ years), and their income status was specified as (1) high, (2) middle, and (3) low.

2.3.2.Nutrition Knowledge Scale: This scale was developed to find out the nutritional knowledge level of adolescents (Melnyk et al., 2009). A scale of 20 items answers each question as "yes", "no" and "do not know".The scales are scored as Yes (1), No (0), No idea (2).The result is the correct answer and is between 1 and 20.The Turkish validity and reliability study of the scale was conducted by Ardiç and Erdogan (2017) and Cronbach's alpha coefficient is 0.84 . The Cronbach's alpha coefficient was found to be 0.70 in this study.

2.3.3.Diet Behavior Scale: This scale was developed to explore the ordinary food consumption of adolescents (Edmundson et al., 1996). The high score on the scale indicates healthy eating habits. Scale scores are -1 for unhealthy food, +1 for healthy food, the total score is between -14 and +14 . The total score obtained from the scale is shown as percentage. It indicates a range from $0 \%$ unhealthy to $100 \%$ healthy food consumption. The Turkish validity and reliability study of the scale was conducted by Haney and Erdoğan (2013). Its test-retest reliability is 0.74 and Cronbach's alpha coefficient is 0.68 . Cronbach's alpha coefficient was found to be 0.63 in the present study.

2.3.4.Children's Dietary Self-Efficacy Scale: This scale measures self-efficacy of adolescents, which helps them choose foods less fat and salt instead of fatty and salty foods (Edmundson et al., 1996). Scale items are valued at $-1,+1$ points (-1: I'm not sure, 0 : a little sure, +1 : very sure), the total score is between -15 and +15 . A higher score indicates higher self-efficacy. The Turkish validity and reliability study of the scale was conducted by Haney and Erdoğan (2013). Its reliability coefficient was 0.79 and the test-retest reliability was 0.68 ; it was found to be 0.77 in the present study.

2.3.5.Exercise Behavior Scale: This scale measures the exercise behaviors of adolescents. It is one of seven subscales of the Adolescent Lifestyle Profile (ALP) Scale (Hendricks, Murdaugh \& Pender, 2006). It is a four-point Likert-type scale with six items. The total score of the scale ranges from 6 to 24. The Turkish validity and reliability study of the scale was conducted by Ardiç and Esin (2015). Its test-retest reliability was 0.84 and its Cronbach's alpha coefficient is 0.80 . Its Cronbach's alpha coefficient was found to be 0.76 in this study.

\subsection{Ethical Considerations}

Approval of the Ethics Committee of Uşak University (No: 54749836-050-01-03/11) was received before the study. Permission was received from the families to use the "Family Information Questionnaire" which they would fill out. While verbal consents of the children were received, written consents of their families were received. They were informed that their identities would be kept confidential and their answers would be anonymous. 
Cangöl Sögüt, S. (2018). Determining the differences in nutrition knowledge, dietary behaviors, physical activity and self-efficacy behaviors based on obesity status among adolescents. Journal of Human Sciences, 15(2), 747-754. doi: $10.14687 /$ ihs.v15i2.5218

\subsection{Statistical Analysis of Data}

While evaluating the data obtained in the study, SPSS 22.0 Statistical packaged software was used for statistical analysis. For the data assessment, descriptive statistical methods (mean, median, number, percentage) were used. Pearson's Chi-Square test was applied for comparison of categorical data. The t-test was performed in between-group comparison of parameters. The confidence interval of $95 \%$ and the significance level of $\mathrm{p}<0.05$ were used to assess the results.

\section{Results}

According to the results, average age of 530 adolescents participating in the study was $10.85 \pm 0.53$ and the age range varied between 10 and $12.50 .9 \%$ of the adolescents were male and according to BMI, 70\% ( $\mathrm{n}=371)$ were found to be normal and $30 \%(\mathrm{n}=159)$ were found to be overweight and obese. In terms of gender, age, income status and mother's educational level, no significant difference was found between the children whose BMI values were normal and overweight/obese ( $\mathrm{p}>0.05)$. In terms of Father's Educational Status, Mother's BMI and Father's BMI, a significant difference was found between the children whose BMI values were normal and overweight/obese. As the Father's educational level, Mother's BMI and Father's BMI increased, the rate of overweight/obese adolescents increased $(p<0.05)$. (Table 1).

Table 1. Socio-demographic characteristics $(n=530)$

\begin{tabular}{|c|c|c|c|c|}
\hline & & $\begin{array}{l}\text { Normal } \\
(n=371)\end{array}$ & $\begin{array}{c}\text { Overweight } \\
\text { / Obese } \\
(\mathrm{n}=159)\end{array}$ & $\mathrm{p}$ \\
\hline & & n ( $\%)$ & n $(\%)$ & \multirow{3}{*}{$\begin{array}{l}\mathrm{X}^{2}=0.036 \\
\mathrm{p}=0.462\end{array}$} \\
\hline \multirow{2}{*}{ Gender } & Female & $181(48.8 \%)$ & $79(49.7 \%)$ & \\
\hline & Male & $190(51.2 \%)$ & $80(50.3 \%)$ & \\
\hline \multirow{3}{*}{ Age } & 10 & $80(21.6 \%)$ & $40(25.2 \%)$ & \multirow{3}{*}{$\begin{array}{l}\mathrm{X}^{2}=3.919 \\
\mathrm{p}=0.141\end{array}$} \\
\hline & 11 & $257(69.3 \%)$ & $112(70.4 \%)$ & \\
\hline & 12 & $34(9.2 \%)$ & $7(4.4 \%)$ & \\
\hline \multirow{3}{*}{ Income Status } & Low & $90(24.3 \%)$ & $32(20.1 \%)$ & \multirow{3}{*}{$\begin{array}{c}X^{2}=3.209 \\
p=0.201\end{array}$} \\
\hline & Moderate & $251(67.7 \%)$ & $107(67.3 \%)$ & \\
\hline & High & $30(8.1 \%)$ & $20(12.6 \%)$ & \\
\hline \multirow{3}{*}{ Mother's Educational Level } & Primary School & $220(59.3 \%)$ & $83(52.2 \%)$ & \multirow{3}{*}{$\begin{array}{c}X^{2}=3.521 \\
p=0.172\end{array}$} \\
\hline & High School & $77(20.8 \%)$ & $33(20.8 \%)$ & \\
\hline & University & $74(19.9 \%)$ & $43(27.0 \%)$ & \\
\hline \multirow{3}{*}{ Father's Educational Level } & Primary School & $158(42.6 \%)$ & $50(31.4 \%)$ & \multirow{3}{*}{$\begin{array}{l}\mathrm{X}^{2}=9.750 \\
\mathrm{p}=0.008^{*}\end{array}$} \\
\hline & High School & $116(31.3 \%)$ & $47(29.6 \%)$ & \\
\hline & University & $97(26.1 \%)$ & $62(39.0 \%)$ & \\
\hline \multirow[t]{2}{*}{ Mother's BMI } & Normal & $186(50.4 \%)$ & $56(35.7 \%)$ & \multirow{2}{*}{$\begin{array}{l}\mathrm{X}^{2}=18.418 \\
\mathrm{p}=0.000 *\end{array}$} \\
\hline & Overweight / Obese & $183(49.6 \%)$ & $101(64.3 \%)$ & \\
\hline \multirow{2}{*}{ Father's BMI } & Normal & $139(37.5 \%)$ & $27(17.1 \%)$ & \multirow{2}{*}{$\begin{aligned} X^{2} & =26.540 \\
p & =0.000^{*}\end{aligned}$} \\
\hline & Overweight / Obese & $232(62.6 \%)$ & $131(82.9 \%)$ & \\
\hline
\end{tabular}


Cangöl Sögüt, S. (2018). Determining the differences in nutrition knowledge, dietary behaviors, physical activity and self-efficacy behaviors based on obesity status among adolescents. Journal of Human Sciences, 15(2), 747-754. doi: $10.14687 /$ ihs.v15i2.5218

It was found that the adolescents' mean score of "exercise behaviors" was $17.457 \pm 3.732$; "nutrition knowledge" mean score was $11.330 \pm 3.258$; "dietary self-efficacy" mean score was 5.138 \pm 5.386; and "dietary behavior" mean score was $3.694 \pm 5.324$. The adolescents' exercise behaviors were high, their self-efficacy behaviors were good, their nutrition knowledge levels and dietary behaviors were at moderate level (Table 2).

Table 2. Descriptive results of the scales

\begin{tabular}{lccccc}
\hline & N & Mean & Sd & Min. & Max. \\
\hline Exercise Behaviors & 530 & 17.457 & 3.732 & 6 & 24 \\
Nutrition Knowledge Score & 530 & 11.330 & 3.258 & 3 & 20 \\
Dietary self-efficacy & 530 & 5.138 & 5.386 & -15 & 15 \\
Dietary Behavior & 530 & 3.694 & 5.324 & -12 & 14 \\
\hline
\end{tabular}

The difference between the group mean scores as a result of t-test conducted to determine whether or not the exercise behavior mean scores of the adolescents showed a significant difference according to the variable of group was not found to be statistically significant $(\mathrm{t}=-1.485$; $\mathrm{p}=0.138>0.05)$.

The correlation between the nutrition knowledge mean score of the adolescents and the variable of group was examined and found to be significant $(t=-4.548 ; \mathrm{p}=0.000<0.05)$. Nutrition knowledge score of adolescents with overweight/obese BMI (12.296 \pm 3.389$)$ was found to be higher than the nutrition knowledge score of adolescents with normal BMI (10.916 \pm 3.114$)$.

The correlation between the dietary self-efficacy mean scores of the adolescents and the variable of group was examined and a significant correlation was found $(t=-3.451 ; \mathrm{p}=0.001<0.05)$. Dietary self-efficacy scores of the adolescents with overweight/obese BMI $(6.359 \pm 5.083)$ were found to be higher than the dietary self-efficacy scores of the adolescents with normal BMI (4.615 \pm 5.434$)$.

The correlation between the dietary bebaviors mean scores of the adolescents and the variable of group was examined and a significant correlation was found $(\mathrm{t}=-2.661 ; \mathrm{p}=0.008<0.05)$. Dietary behavior scores of the adolescents with overweight/obese BMI (4.629 \pm 5.466$)$ were found to be higher than the dietary behavior scores of adolescents with normal BMI (3.294 \pm 5.218$)$ (Table 3).

Table 3. Distribution of the Adolescents in Terms of Scales

\begin{tabular}{|c|c|c|c|c|}
\hline & $\begin{array}{l}\text { Normal } \\
(\mathrm{n}=371)\end{array}$ & $\begin{array}{l}\text { Overweight / Obese } \\
(\mathrm{n}=159)\end{array}$ & \multirow[t]{2}{*}{$\mathbf{t}$} & \multirow[t]{2}{*}{$\mathrm{p}$} \\
\hline & Mean \pm Sd & Mean \pm Sd & & \\
\hline Exercise Behaviors & $17.299 \pm 3.747$ & $17.824 \pm 3.681$ & -1.485 & 0.138 \\
\hline Nutrition Knowledge Score & $10.916 \pm 3.114$ & $12.296 \pm 3.389$ & -4.548 & $0.000 *$ \\
\hline Dietary self-efficacy & $4.615 \pm 5.434$ & $6.359 \pm 5.083$ & -3.451 & $0.001 *$ \\
\hline Dietary Behavior & $3.294 \pm 5.218$ & $4.629 \pm 5.466$ & -2.661 & $0.008 *$ \\
\hline
\end{tabular}

$*_{\mathrm{p}}<0.05 ;$ t-test

\section{Discussion}

This study was conducted to specify the differences in adolescents' nutrition knowledge, dietary behaviors, physical activity, and self-efficacy behaviors based on obesity status. In the study, $30 \%$ of the adolescents $(n=159)$ were found to be overweight and obese. 42 million of children under the age of 5 years all around the world are overweight and obese. The prevalence of childhood obesity doubled between 1980 and 2014 (WHO, 2016). In the United States of America, obesity rate in children and adolescents aged between 2 and 19 years is approximately $17 \%$, and 12.7 million children and adolescents in the last 10 years have been affected from obesity (CDC, 2016). According to KNHANES's study, $16.3 \%$ of the adolescents are overweight and obese 
Cangöl Sögüt, S. (2018). Determining the differences in nutrition knowledge, dietary behaviors, physical activity and self-efficacy behaviors based on obesity status among adolescents. Journal of Human Sciences, 15(2), 747-754. doi: $10.14687 /$ ihs.v15i2.5218

(KNHANES, 2013). All these studies confirm that obesity is not still at the desired level for the health of adolescents.

Being overweight and obese for adolescents differs according to the father's educational status and parents' BMI values. As Father's educational level, Mother's BMI and Father's BMI increase, the rate of overweight/obese adolescents increases. The studies have shown that dietary habits of children are influenced by their parents' dietary habits (Scaglioni, Salvioni, \& Galimberti, 2008) and the most important factor in the increase of BMI in children is the parents' BMI (Haney and Erdoğan, 2013).

In this study, it was found that while nutrition knowledge levels and dietary behaviors of the adolescents were at moderate level, their dietary self-efficacy behaviors were at good level. Contrary to expectations, nutrition knowledge, dietary self-efficacy perception and dietary behaviors in overweight and obese adolescents were found to be high compared to the other adolescents in this study. However, the studies have indicated that these three items are the main determinants for developing obesity prevention behaviors and even the presence of only one of these would not be sufficient to prevent obesity (Prochaska, Spring, and Nigg, 2008; Di Noia et al., 2006; Driskell, Dyment, Mauriello, Castle, and Sherman, 2008). This result may be due to the fact that adolescents and parents in the overweight and obese group are more cautious about nutritional behavior. In addition, it is thought that effective and continuous nutrition training is necessary for adolescents to covert the information taught into behaviors. Studies support that nutritional behavior is higher in the overweight and obese group (Ha et al. 2016; Lee, Jeong \& Park, 2003).The studies have reveal that there is no difference between the normal weight and overweight/obese groups in terms of adolescents' nutrition knowledge (Ha et al., 2016; Şanlier, Konaklığlu \& Güçer,2009). Self-efficacy behaviors are lower in the overweight and obese group (Ha et al., 2016). This is inconsistent with the results of this study. In addition, the nutritional information and nutritional behavior levels of all adolescents are moderately general in general, which raises the need for education.

Exercise behaviors of the adolescents were high in this study. No significant difference was found between normal weight and overweight / obese group based on exercise behavior in this study. In the study by $\mathrm{Ha}$ et al., the exercise behaviors were found to be lower in overweight and obese adolescents (Ha et al., 2016).

\section{Limitations}

The sample group was selected from a city in the western region of Turkey. Therefore, it cannot be generalized to all adolescents living in Turkey. The accuracy of self-report data is limited to the statements of adolescents.

\section{Conclusions}

In the study, $30 \%(\mathrm{n}=159)$ of the adolescents were found to be overweight and obese. When the status of adolescents to be overweight and obese was examined in terms of sociodemographic characteristics, they did not differ in terms of gender, age, income status and mother's educational level. However, they differed according to father's educational level and mother's and father's BMI. As Father's education level, Mother's BMI and Father's BMI increased, the rate of overweight/obese adolescents increased as well.

It was found in this study that while the nutrition knowledge levels and dietary behaviors of the adolescents were at moderate level, dietary self-efficacy behaviors were at good level. In this study, nutrition knowledge, dietary self-efficacy perception, and dietary behaviors were found to be higher in overweight and obese adolescents compared to other adolescents. However, the exercise behaviors of adolescents were higher in this study. There was no significant difference between normal weight and overweight/obese groups based on exercise behaviors in this study. 
Cangöl Sögüt, S. (2018). Determining the differences in nutrition knowledge, dietary behaviors, physical activity and self-efficacy behaviors based on obesity status among adolescents. Journal of Human Sciences, 15(2), 747-754. doi: $10.14687 /$ ihs.v15i2.5218

Nutrition knowledge, dietary behaviors, dietary self-efficacy and exercise behaviors are the most important determinants in obesity prevention programs in adolescents. Nutrition knowledge is one of the factors that affect nutritional status and habits of individuals, families and communities. Therefore, the place and importance of nutrition education is great in protecting and promoting health. All adolescents' nutritional knowledge and nutritional behavior scores were moderate. Nutrition knowledge, nutritional behavior and nutrition self-efficacy scores were high in overweight / obese adolescents. It can be said that obese adolescents can not turn into information behaviors. Attempts can be made for this. In this regard, larger studies can be suggested.

\section{Acknowledgment}

The author are grateful for the support of all the students who participated in the study.

\section{Conflicts of Interest}

The author declare no conflict of interest.

\section{References}

Ardıç, A. \& Erdoğan, S. (2017). The effectiveness of the COPE healthy lifestyles TEEN program: a school based intervention in middle school adolescents with 12-month follow-up. Journal of Advanced Nursing, 73(6),1377-1389. doi: 10.1111/jan.13217.

Ardıç, A. \& Esin, M.N. (2015). The Adolescent Lifestyle Profile scale: reliability and validity of the Turkish version of the instrument. The Journal of Nursing Research, 23(1), 33-40.

Bundak, R.,Furman, A., Gunaz, H.,Darendeliler, F., \&Bas, F. Neyzi, O. (2006). Body mass index references for Turkish children. Acta Paediatrica, 95, 194-198.

Centers for Disease Control and Prevention [CDC]. (2016). Childhood Obesity Facts Erişim Tarihi: 30.11.2017, https://www.cdc.gov/obesity/data/childhood.html.

Çocukluk Çağı Obezite Araştırması Ön Rapor (COSI-TR) (2013). Erişim 13.11.2014, http://www.diabetcemiyeti.org/var/cdn/a/f/cosi-tr-sonuclari.pdf.

Di Noia, J., Schinke, S.P., Prochaska, J.O. , \& Contento, I.R. (2006).Application of the transtheoretical model to fruit and vegetable consumption among economically disadvantaged African-American adolescents: preliminary findings. Am J Health Promot., 20, 342-348.

Driskell, M.M., Dyment, S., Mauriello, L., Castle, P. \& Sherman, K.(2008). Relationships among multiple behaviors for childhood and adolescent obesity prevention Preventive Medicine, 46, 209-215.

Edmundson, E., et al. (1996). The effects of the child and adolescent trial for cardiovascular health upon psychosocial determinants of diet and physical activity behavior. Preventive Medicine, 25 (4), 442-454.

Forneris, T., Fries, E., Meyer, A., Buzzard, M., Uguy, S., Ramakrishnan, R., et. al. (2010). Results of a rural school-based peer-led intervention for youth: goals for health. J Sch Health, 80, 2.

Ha, S. A., Lee, S. Y., Kim, K. A., Seo, J. S., Sohn, C. M., Park, H. R., et. al. (2016). Eating habits, physical activity, nutrition knowledge, and self-efficacy by obesity status in upper-grade elementary school students. Nutrition research and practice, 10(6), 597-605. doi: 10.4162/nrp.2016.10.6.597

Haney, M.Ö. \& Erdoğan, S. (2013). Factors related to dietary habits and body mass index among Turkish school children: a Cox's interaction model-based study. Journal of Advanced Nursing, 69 (6), 1346-1356. doi: 10.1111/j.1365-2648.2012.06126.x.

Hendricks C.S., Murdaugh C. \& Pender N.J. (2006). The adolescent lifestyle profile: development and psychometric characteristics. Journal of National Black. Nurses Association, 17 (2), 1-5. 

self-efficacy behaviors based on obesity status among adolescents. Journal of Human Sciences, 15(2), 747-754. doi:10.14687/jhs.v15i2.5218

Horwath, C.C.,Nigg C.R., Wong, K.T. \& Dishman, R. K. ( 2010). Investigating fruit and vegetable consumption using thetranstheoretical model. American Journal of Health Promotion, 24(5), 324-333.

Lee HS, Jeong WS, Park UI. (2003). The dietary behavior of obese and normal weight elementary school children with maternal guidance for their dietary behavior. Korean J Community Nutr, 8,831-9.

Melnyk B.M., Jacobson D., Kelly S., O’Haver J., Small L. \& Mays M.Z. (2009) Improving the mental health, healthy lifestyle choices and physical health of hispanic adolescents: a randomized controlled pilot study. Journal of School Health 79 (12),575-584.

Ministry of Health and Welfare, Korea Centers for Disease Control and Prevention. Korea Health Statistics 2013: Korea National Health and Nutrition Examination Survey (KNHANES VI1). Cheongju: Korea Centers for Disease Control and Prevention; 2014.

Prochaska, J.O., Spring, B., \&Nigg, C.R. (2008). Multiple health behavior change research: An introduction and overview. Prev Med., 46(3), 181-188.

Scaglioni, S., Salvioni, M., \& Galimberti,C. (2008). Influence of parental attitudes in the development of children eating behavior. British Journal of Nutrition, 99, Suppl. 1, S22S25. doi: 10.1017/S0007114508892471.

Sağlık Bakanlığı [SB], Hacettepe Üniversitesi Sağllk Bilimleri Fakültesi Beslenme ve Diyetetik Bölümü, T.C. Milli Eğitim Bakanlı̆̆ı. (2011). Türkiye’de Okul Çağı Çocuklarında (6-10 Yaş Grubu) Büyümenin İzlenmesi Projesi Araştırma Raporu (TOÇBI). Kuban Matbaacıllk, Sağllk Bakanlığı Yayın No: 834, ISBN: 978-975-590-370-5. Ankara.

Şanlıer, N., Konaklıoğlu, E., \& Güçer, E. (2009). Gençlerin beslenme bilgi, alışkanlık ve davranışları ile beden kütle indeksleri arasındaki ilişki. Gaæ̧i Üniversitesi Gą̧i Ë̆itim Fakültesi Dergisi, 29(2).

Wagner, D. \& Bear, M. (2009). Patient satisfaction with nursing care: a concept analysis within a nursing framework. Journal of Advanced Nursing, 65(3), 692-701.

World Health Organization [WHO] (2016). Obesity and overweight fact sheet. Erişim 16.12.2017. http://www.who.int/mediacentre/factsheets/fs311/en/. 